\title{
Computational methods for the investigation of ski boots ergonomics
}

\author{
Chiara Giulia Fontanella ${ }^{1,2} \cdot$ Alessandro Arduino $^{3} \cdot$ Ilaria Toniolo $^{1} \cdot$ Claudio Zampieri $^{4} \cdot$ Lorenzo Bortolan $^{5,6}$. \\ Emanuele Luigi Carniel ${ }^{1,2}$
}

Accepted: 15 June 2021 / Published online: 25 June 2021

(c) The Author(s) 2021

\begin{abstract}
Ski boots are known to cause vasoconstriction in the wearer's lower limbs and, thus, cause a "cold leg" phenomenon. To address this problem, this work provides a computational framework for analysing interactions between the ski boot and the lower limb. The geometry of the lower limb was derived from magnetic resonance imaging and computed tomography techniques and anthropometric data. The geometry of the ski boot shell was obtained by means of three-dimensional computer aided design models from a manufacturer. Concerning the ski boot liner, laser scanning techniques were implemented to capture the geometry of each layer. The mechanical models of the ski boot and the lower limb were identified and validated by means of coupled experimental investigations and computational analyses. The computational models were exploited to simulate the buckling process and to investigate interaction phenomena between the boot and the lower limb. Similarly, experimental activities were performed to further analyse the buckling phenomena. The obtained computational and experimental results were compared regarding both interaction pressure and displacements between the buckle and the corresponding buckle hooks. These comparisons provided reasonable agreement (mean value of discrepancy between the model and mean experimental results in the tibial region: $20 \%$ ), underlining the model's capability to correctly interpret results from experimental measurements. Results identified the critical areas of the leg, such as the tibial region, the calcaneal region of the foot and the anterior sole, which may suffer the most due to the hydrostatic pressure and compressive strain exerted on them. The results highlight that computational methods allow investigation of the interaction phenomena between the lower leg and ski boot, potentially providing an effective framework for a more comfortable and ergonomic design of ski boots.
\end{abstract}

Keywords Biomechanics for Sport Equipment Design · Mechanics of Biological Tissues · Computational Biomechanics · Vasoconstriction Phenomena

This article is a part of Topical Collection in Sports Engineering on Winter Sports, edited by Dr. Aimee Mears, Dr. David Pearsall, Dr. Irving Scher and Dr. Carolyn Steele.

Emanuele Luigi Carniel emanueleluigi.carniel@unipd.it

1 Department of Industrial Engineering, University of Padova, Centre for Mechanics of Biological Materials, Via Venezia, 1, 35131 Padova, Italy

2 Centre for Mechanics of Biological Materials, University of Padova, Padova, Italy

3 Department of Civil Environmental and Architectural Engineering, University of Padova, Padova, Italy

4 Tecnica Group S.P.A, Giavera del Montello, Treviso, Italy

5 Department of Neurosciences Biomedicine and Movement Sciences, University of Verona, Verona, Italy

6 CeRiSM - Research Center Mountain Sport \& Health, University of Verona, Verona, Italy

\section{Introduction}

Alpine skiing is one of the most popular winter sports [1]. From a biomechanical viewpoint, ski boots are the most important piece of ski equipment [2]. Many factors determine ski boot comfort and ergonomics, particularly liner materials and structures. Previous studies demonstrated the influence of ski boot structure on heat and moisture transfer phenomena [3, 4]. Furthermore, ski boots are known to generate vasoconstrictive phenomena on the wearer's lower limbs, thus causing a "cold leg" sensation [5-7] and compromising ergonomics and comfort.

Ski boot buckling determines strain and stress fields within lower limb soft tissues, which may cause the vasoconstriction phenomena. Tools that enable the analysis of such stress and strain fields can be highly relevant. Experimental activities may provide preliminary information about the 
interaction phenomena between the ski boot and lower limb. For example, pressure sensors can be applied to measure the interaction pressure between the lower limb and ski boot at specific points $[8,9]$. On the other hand, computational methods are extensively used for structural investigation of different parts of the ski boot leading to more refined and detailed results in a more efficient way. Moreover, computational approach enables a wider and deeper investigation, providing the continuous distribution of interaction pressure and effective data about stress and strain within biological tissues [10].

The aim of this work was to develop a finite element model of the interaction between the ski boot and the lower limb, to asses and to analyse pressures, strains and stresses characterising this interaction. Mechanical stimulation of soft tissue is mainly influenced by the following two factors: (a) the ski boot's geometrical configuration and materials, and (b) the wearers' lower limb anatomy and morphometry. A reliable computational framework must account for such parameters, with the goal to improve ski boot's comfort and user's ergonomics. Experimental tests were developed to validate the computational model.

\section{Materials and methods}

The in silico investigation of ski boot ergonomics and comfort has been developed by coupling experimental and computational activities. A general overview of the activities is reported in Fig. 1. The preliminary actions pertained to the development of lower limb and ski boot computational models. The coupling of such models entailed the computational analysis of ski boot buckling. Contemporarily, experimental measurements of the interface pressure between the lower limb and ski boot from buckling have been developed. The comparison of experimental and computational results made it possible to assess the dependability of the models. Finally, post-processing of computational results provided information about the mechanical stimulation of lower limb biological tissues, which allow evaluating ski boot comfort and ergonomics.

\subsection{Finite element model of the lower limb}

To obtain the three-dimensional computer aided design (3D CAD) model of the lower limb, computed tomography (CT) (NewTom/NTVGiMK4, 3 mA, 110 kV, 0.3 mm cubic voxels) and magnetic resonance imaging (MRI) (3 T Siemens Magnetom Trio, fat-suppressed 3D dual echo steady state (DESS) sequence with $0.7 \mathrm{~mm}$ isotropic resolution, size matrix $320 \times 576 \times 104, \mathrm{TE} / \mathrm{TR}=5.5 / 13 \mathrm{~ms}$, flip angle

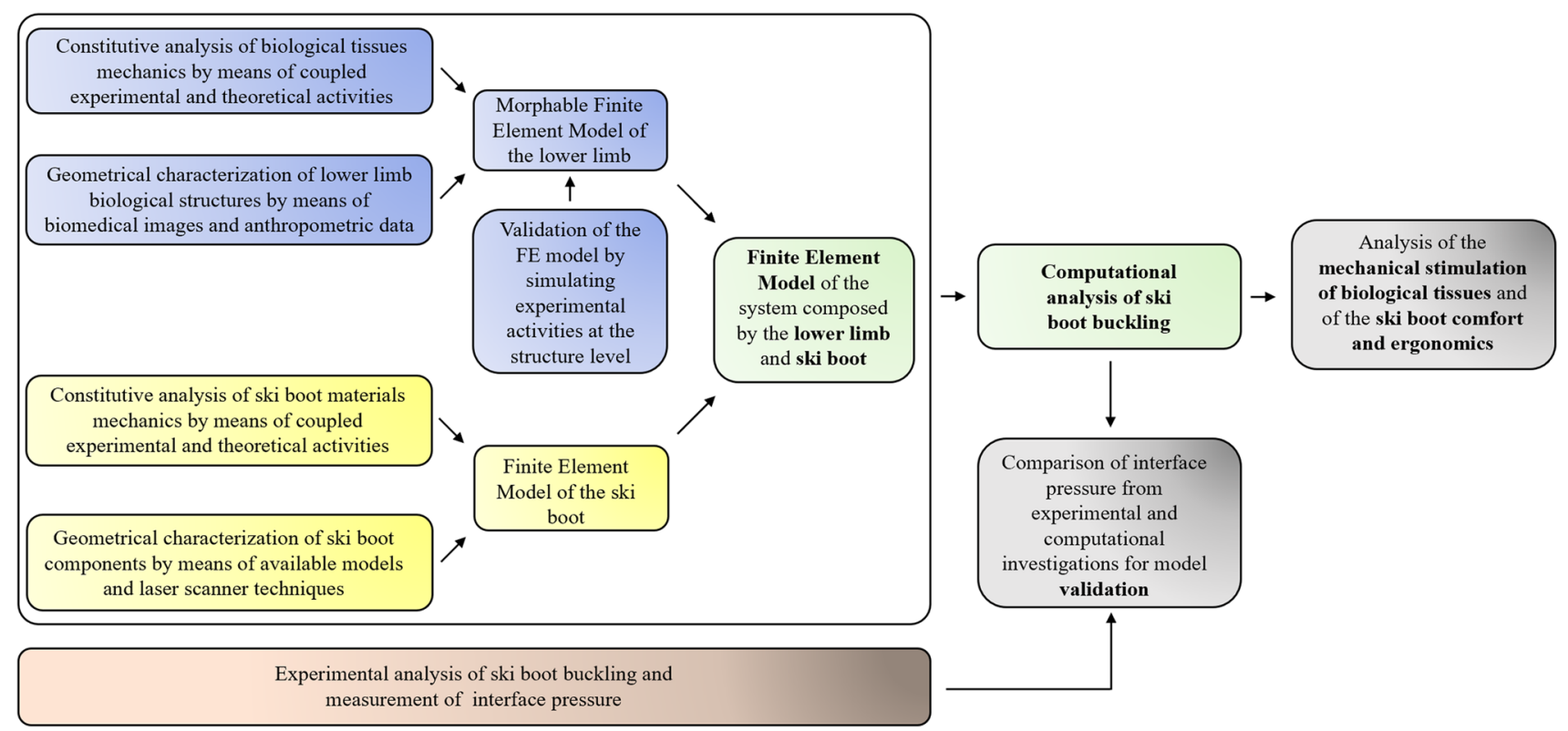

Fig. 1 Flowchart of the activities: computational modelling of lower limb (blue boxes; Sect. 2.1) and ski boot (yellow boxes; Sect. 2.2); models coupling and computational analysis of ski boot buckling (green boxes; Sect. 2.3); experimental investigation of interface pres- sure (pink box; Sect. 2.4); model validation and exploitation for the evaluation of ski boot comfort and ergonomics (grey boxes; Sects. 3, 4) 
25 degrees, $\mathrm{TA}=5 \mathrm{~min}$ ) images of a Caucasian male (age: 30 years; height: $175 \mathrm{~cm}$; weight: $77 \mathrm{~kg}$; foot EU size: 42) were acquired in a no-load set-up. The specific person was informed about the purpose and procedures of the study, and signed an informed consent for processing the resulting models from anonymised biomedical images. In details, biomedical images were processed by means of segmentation techniques to obtain stereolithography (STL) triangulated models. With the process of segmentation, models obtained may be characterised by irregular triangulated surfaces, with gaps and scattering due to the stratification of the biomedical images. For this purpose, the first step involved the regularisation of the surface (Simpleware, Synopsys Corporate, Mountain View, California, USA), starting from the operation of smoothing that solves the minor defects, while maintaining the overall shape. On the other side, the surfaces that presented relevant discontinuity were selected, deleted and replaced with a regular shape that continuously followed the trend of the surrounding region. Subsequently, triangulated surfaces were interpolated by means of free-form surfaces (UGS NX, Siemens PLM Software, Plano, Texas, USA). The process led to free-form 3D CAD models of the main biological components of the lower limb, such as bones, adipose tissue, calf muscle, Achilles' tendon and skin.

The availability of average morphometric data [11-17] and the use of morphing techniques $[18,19]$ made it possible to obtain an accurate and reliable geometry of a typical adult male (lower leg length $=530 \mathrm{~mm}[16]$; calf circumference $=395 \mathrm{~mm}$ [13]; long heel length $=126 \mathrm{~mm}$ [14]; foot length $=260 \mathrm{~mm}$ [17]; ball width $=102 \mathrm{~mm}$ [17]) (Fig. 2a). Furthermore, morphometric data permitted to add biological structures that are not easily and accurately identifiable through MRI or CT images, such as cartilages [20] and ligaments [21]. The main cartilages and ligaments of the ankle joints were 3D modelled, while truss elements were used to provide simplified links among the other bony elements, with particular regard to the metatarsal and phalangeal regions [22]. The model was defined accounting for the possibility to morph the geometry on the basis of subject specific characteristics, with specific regard to the anatomical properties reported in Fig. 2a. On the other side, the specific dimension of some biological structures, such as ligaments and cartilages, must be defined based on anatomical considerations and data. The initial angle between the floor and tibia was defined by considering a relaxed position that is usually assumed during the ski boot wearing and buckling, such as $77^{\circ}$ that was experimentally measured, as fully reported in Sect. 2.4.

The resulting 3D CAD model was discretised in the pre-processing environment Abaqus CAE 2018 (Dassault Systèmes, France) using four-node linear tetrahedral finite elements. With regard to the different regions of the model, different mesh discretization levels and techniques were assumed. Specific sensitivity analyses have been performed
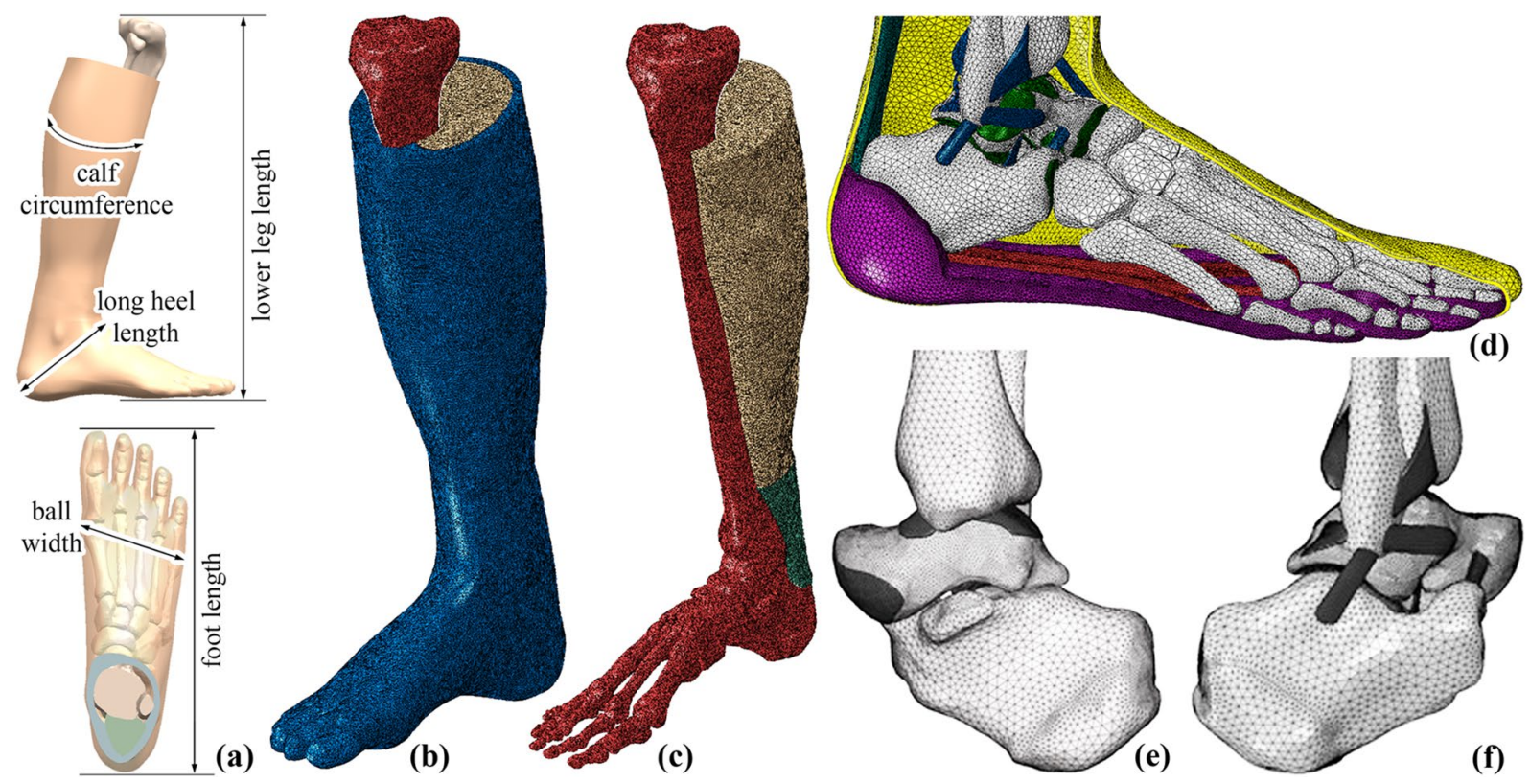

Fig. 2 Virtual solid and finite element modelling of the lower limb: a anthropometric reference data (lower leg length $=530 \mathrm{~mm} \mathrm{[16];} \mathrm{calf}$ circumference $=395 \mathrm{~mm}$ [13]; long heel length $=126 \mathrm{~mm} \mathrm{[14]}$; foot length $=260 \mathrm{~mm}$ [17]; ball width $=102 \mathrm{~mm}$ [17]); b complete geometry (blue: skin and subcutaneous loose tissue; red: bony elements; light brown: calf muscle), $\mathbf{c}$ internal view of bony elements (red), calf muscle (light brown) and Achilles tendon (azure), d details of some of the foot structures (azure: Achilles tendon; blue: ligaments; green: cartilages; red: plantar fascia; violet: plantar tissues; yellow: skin), details of e cartilages (dark grey) and $\mathbf{f}$ ligaments (dark grey) of the tibiotalar joint 
aiming to define the optimal element size, by considering both the quality of the computational results and the computational effort of the model. In this sense, the average size of the elements varied to discretize in the best way the geometry and the level of details of each model subcomponent (ranging between 0.05 and $1.00 \mathrm{~mm}$ ) (Fig. 2b-f).

Concerning the mechanical behaviour of the biological tissues, the soft tissues were differentiated from the hard ones, giving the latter a rigid formulation [23]. This choice did not alter the model's dependability because the forces generated due to the lower limb and the ski boot interaction do not strain the bone structure substantially. Moreover, the rigid body assumptions reduced the computational effort of the model, permitting to analyse the strains of soft tissues, which are mainly involved in vasoconstriction and whose magnitude is typically greater than that of bony elements.

Concerning the soft tissues, their mechanical response must account for large strains and displacements. Furthermore, such tissues are known to exhibit non-linear elastic behaviour as well as time dependent effects. For these reasons, these tissues were assigned hyperelastic or viscohyperelastic behaviour using both isotropic and anisotropic formulations depending on the specific tissue [24]:

$\mathbf{S}\left(\mathbf{C}, \mathbf{q}^{i}\right)=2 \frac{\partial W^{0}(\mathbf{C})}{\partial \mathbf{C}}-\sum_{i} \mathbf{q}^{i}(\mathbf{C}, t)$,

where $\mathbf{S}$ is the second Piola-Kirchhoff stress tensor, $\mathbf{C}$ is the right Cauchy Green strain tensor and $\mathbf{q}^{i}$ are viscous variables. $W^{0}$ is a strain energy function that specifies the instantaneous hyperelastic behaviour of the tissue, and can assume isotropic or anisotropic conformations. $W^{0 m}$ is the isotropic contribution, while $W^{0 f}$ provides anisotropic features from fibres families that are initially oriented along directions $\mathbf{a}_{0}$ ${ }^{j}[25]:$

$W^{0}(\mathbf{C})=W^{0 m}(\mathbf{C})+\sum_{j} W^{0 f}\left(\mathbf{C}, \mathbf{a}_{0}^{j}\right)$.

Standard differential equations define the evolution of viscous variables, which specify relaxed stress components, depending on viscous parameters, such as relative stiffens $\gamma^{i}$ and relaxation time $\tau^{i}[26]$ :

$\dot{\mathbf{q}}^{i}+\frac{1}{\tau^{i}} \mathbf{q}^{i}=2 \frac{\gamma^{i}}{\tau^{i}} \frac{\partial W^{0}}{\partial \mathbf{C}}$.

With regard to the different tissues, the specific model formulation and the identification of the associated constitutive parameters required relevant efforts. They mainly concerned to the specific mathematical definition of the strain energy function of Eq. (2) on the basis of tissue histology and preliminary data about tissue mechanics, the identification of the associated constitutive parameters by means of the inverse analysis of mechanical tests [10], and the computational implementation of the constitutive formulation by means of "ad hoc" computational subroutines. Specific references to constitutive analyses and experimental investigations are reported in Table 1.

Finally, frictionless contact conditions and tie constraints defined the interactions among soft and bony elements, depending on the specific situation. Specifically, tie constraint ensured continuity among skin and adipose tissues, between bone and cartilages or ligaments/tendons insertions, and between skin, calf muscle and Achilles' tendon. The final finite element discretization of the lower limb structures led to about 3 million four-node tetrahedral elements, 700,000 nodes and 2.5 million variables.

Table 1 Constitutive analysis of the lower limb principal tissues: constitutive formulations and experimental tests for parameters identification

\begin{tabular}{|c|c|c|}
\hline Tissue & Constitutive formulation & Experimental activities \\
\hline $\begin{array}{l}\text { Plantar adipose tissue (heel pad and } \\
\text { forefoot regions) }\end{array}$ & Isotropic visco-hyperelastic [27-30] & $\begin{array}{l}\text { Unconfined compression tests }[31,32] \\
\text { Shear tests [33] } \\
\text { Stress relaxation tests }[34]\end{array}$ \\
\hline Ankle joint cartilages & Anisotropic hyperelastic [20] & Indentation tests [35] \\
\hline Plantar fascia & Anisotropic visco-hyperelastic [36] & Tensile tests and stress relaxation tests $[37,38]$ \\
\hline Ankle ligaments & Anisotropic visco-hyperelastic $[21,39]$ & $\begin{array}{l}\text { Tensile tests at different strain rates and along dif- } \\
\text { ferent loading directions [40-42] } \\
\text { Shear tests [43] }\end{array}$ \\
\hline Other ligaments & Linear elastic truss elements [44] & Tensile tests [45] \\
\hline $\begin{array}{l}\text { Loose soft tissues of the foot and } \\
\text { subcutaneous tissue }\end{array}$ & Isotropic hyperelastic [46] & Indentation tests [47] \\
\hline Achilles tendon & Anisotropic hyperelastic [48] & $\begin{array}{l}\text { Tensile tests }[49,50] \\
\text { Compression tests }[51]\end{array}$ \\
\hline Muscular tissue of the calf & Anisotropic hyperelastic - passive behaviour & $\begin{array}{l}\text { Tensile tests along different loading directions [52] } \\
\text { Structural compression tests [53] }\end{array}$ \\
\hline Skin & Anisotropic hyperelastic [54] & $\begin{array}{l}\text { Tensile tests along different loading directions [55] } \\
\text { Compression tests }[56,57]\end{array}$ \\
\hline
\end{tabular}


Before exploiting the computational model of the lower limb for predictive investigations, its reliability must be assessed. The evaluation of such dependability usually requires analysing further experimentations, which must have been performed at the structure level. The comparison between model and experimental results finally claims the capability of the model to actually predict the mechanical behaviour of the biological structure. Because of the complexity of the overall model and the lack of experimentations on the overall lower limb, specific experimental activities on different anatomical structures were investigated. To validate the mechanical model of the calcaneal region, computational analyses simulated indentation tests, with regard to both in vitro [59] and in vivo [61, 62] conditions. Fig 3a, b report the experimental and the computational set-up, respectively, while in Fig. $3 c$ the comparison between model and experimental results is provided. The dependability of the ankle joint model required simulating typical clinical tests, like the dorsiflexion and the plantarflexion tests [39], and the anterior drawer and the talar tilt tests [63]. Again, Fig. 3d-f provides an overview of the experimental and computational experimentations, while experimental and model results are compared in Fig. 3g, h. Aiming to further assess the effectiveness of the foot model, the different steps of the gait cycle were analysed [22].

\subsection{Finite element model of the ski boot}

The development of the 3D CAD model of the ski boot involved processing of aesthetic virtual solid models (Fig. 4a) that were provided by a boot manufacturer, with particular regard to shell components. The manufacturer provided an STL model that they mainly use for marketing purposes, which was interpolated by means of free-form surfaces. Laser scanner techniques were also exploited to develop a model of the liner and the cuff. Even though the procedure was performed on a specific product, it can be applied to model other ski boots. The size of the ski boot was $26 \mathrm{~cm}$ (Mondopoint sizing system), the internal width in the wider section (LAST) was $100 \mathrm{~mm}$ and the nominal flex index was 130, as stated by the manufacturer.

As previously reported, the provided geometric models of the shells were rendered using STL techniques and interpolated by means of free-form surfaces (Fig. 4b). The
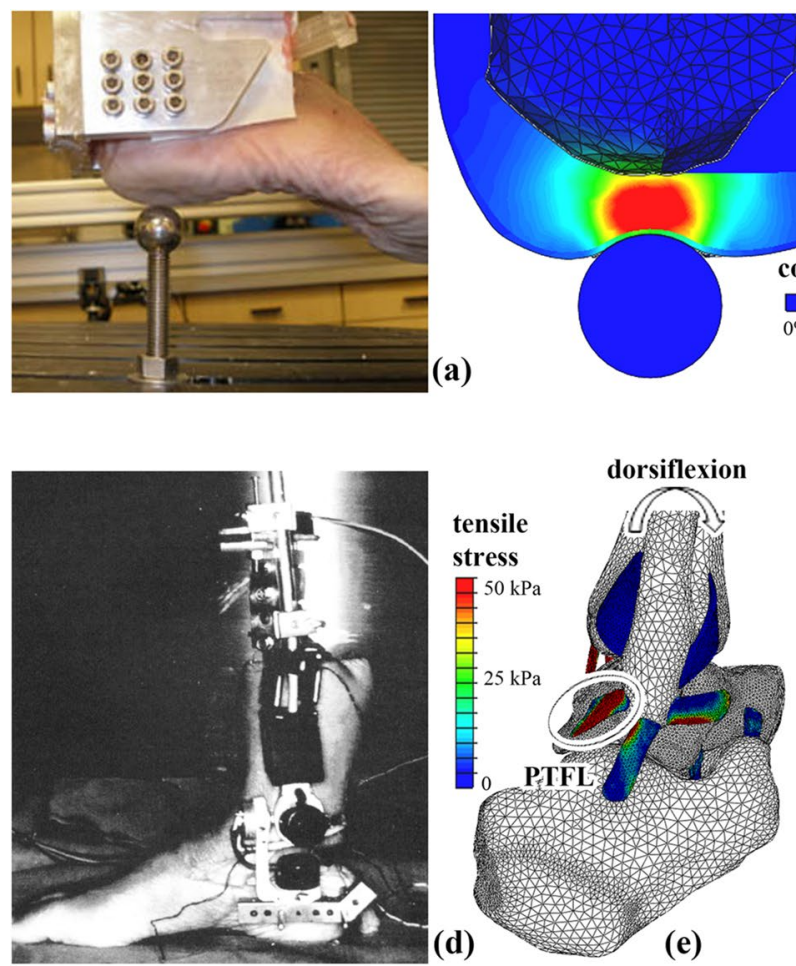

Fig. 3 Examples of coupled experimental and computational activities for lower limb model validation. Indentation of calcaneal region: a experimental set-up by Erdemir et al. (2009) [58] b contour of compressive strain from computational analysis; c comparison of computational results (continuous lines) and median experimental data (empty circles): computational simulations have been performed assuming the principal set of constitutive parameters (middle grey
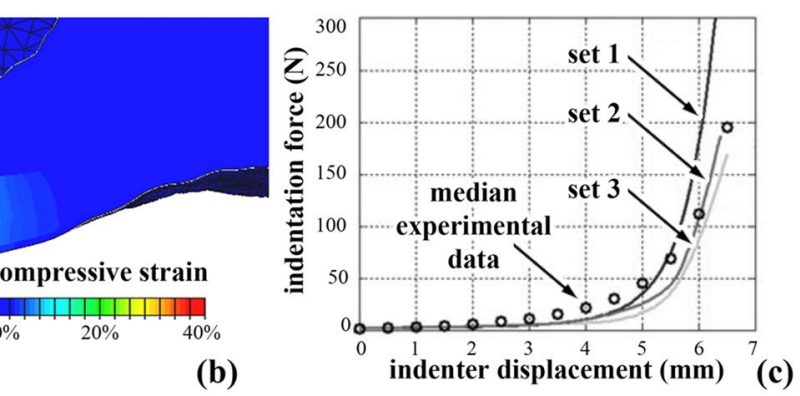

(b)
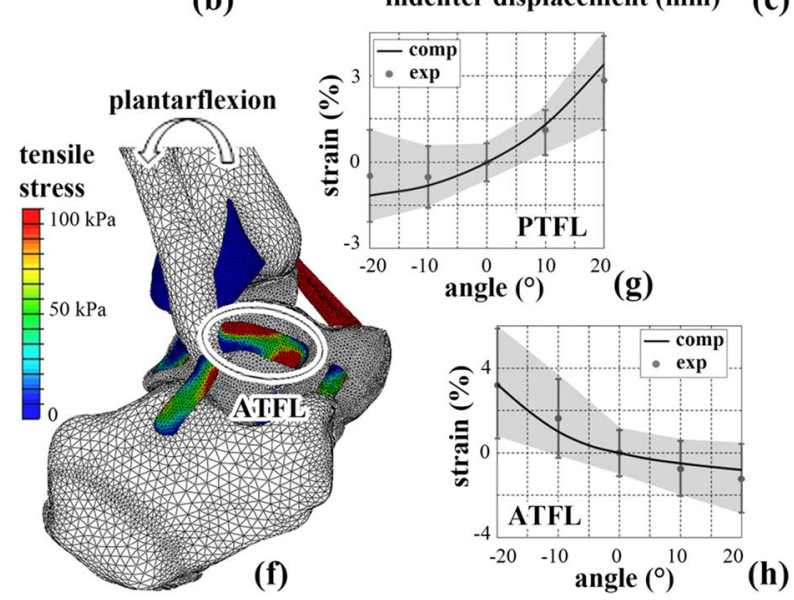

line), while two other sets of constitutive parameters (light and dark grey lines) were investigated aiming to provide a sensitivity analysis of the model [59]. Dorsiflexion and plantarflexion tests: d experimental set-up by Ozeki et al., (2002) [60]; e,f contours of tensile stress within ankle ligaments from computational analyses; g,h comparison of model results and experimental median data with $50 \%$ scatter bands [39] 

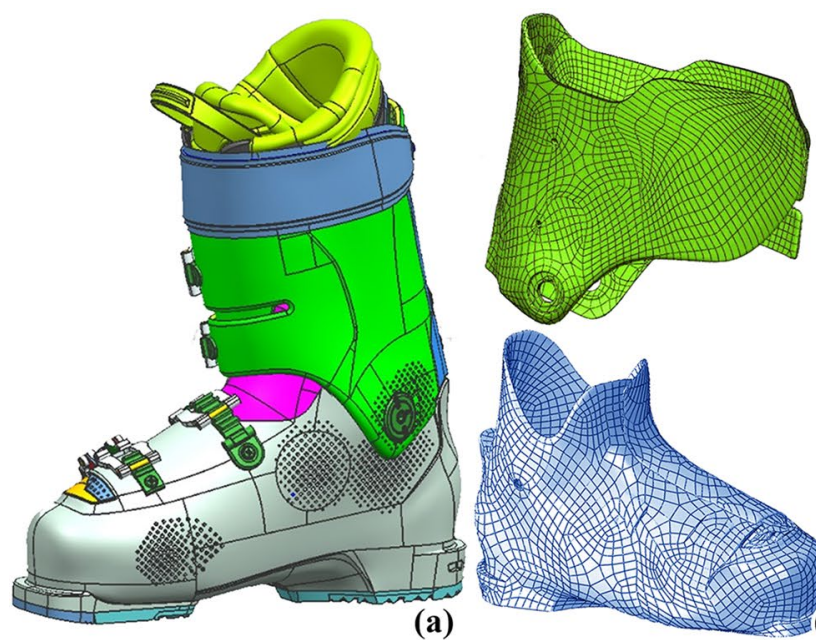

(a)
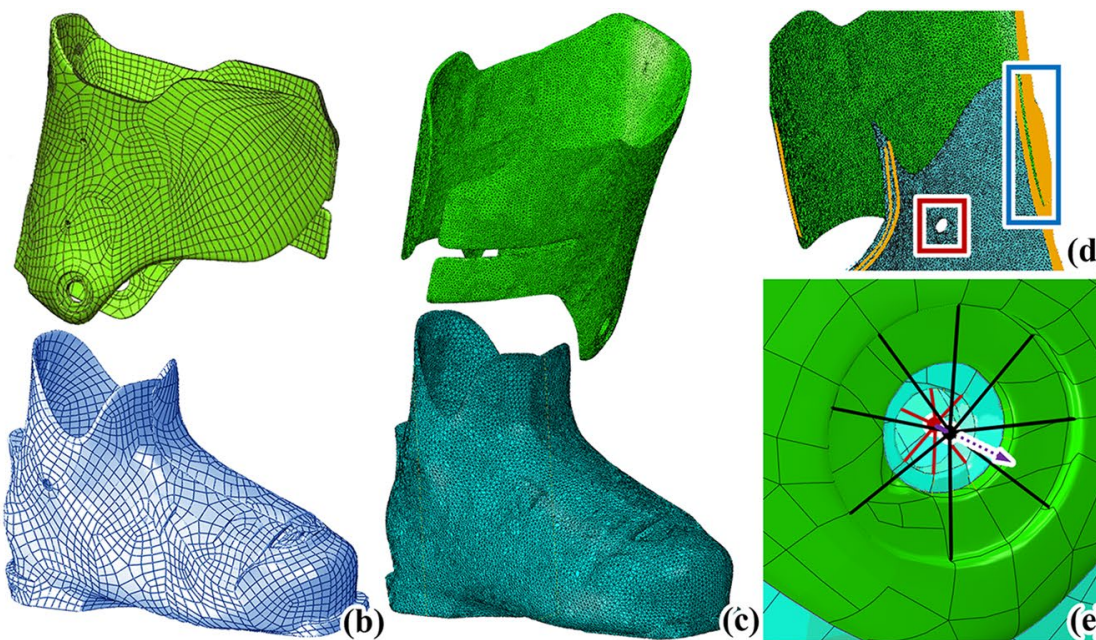

(d)
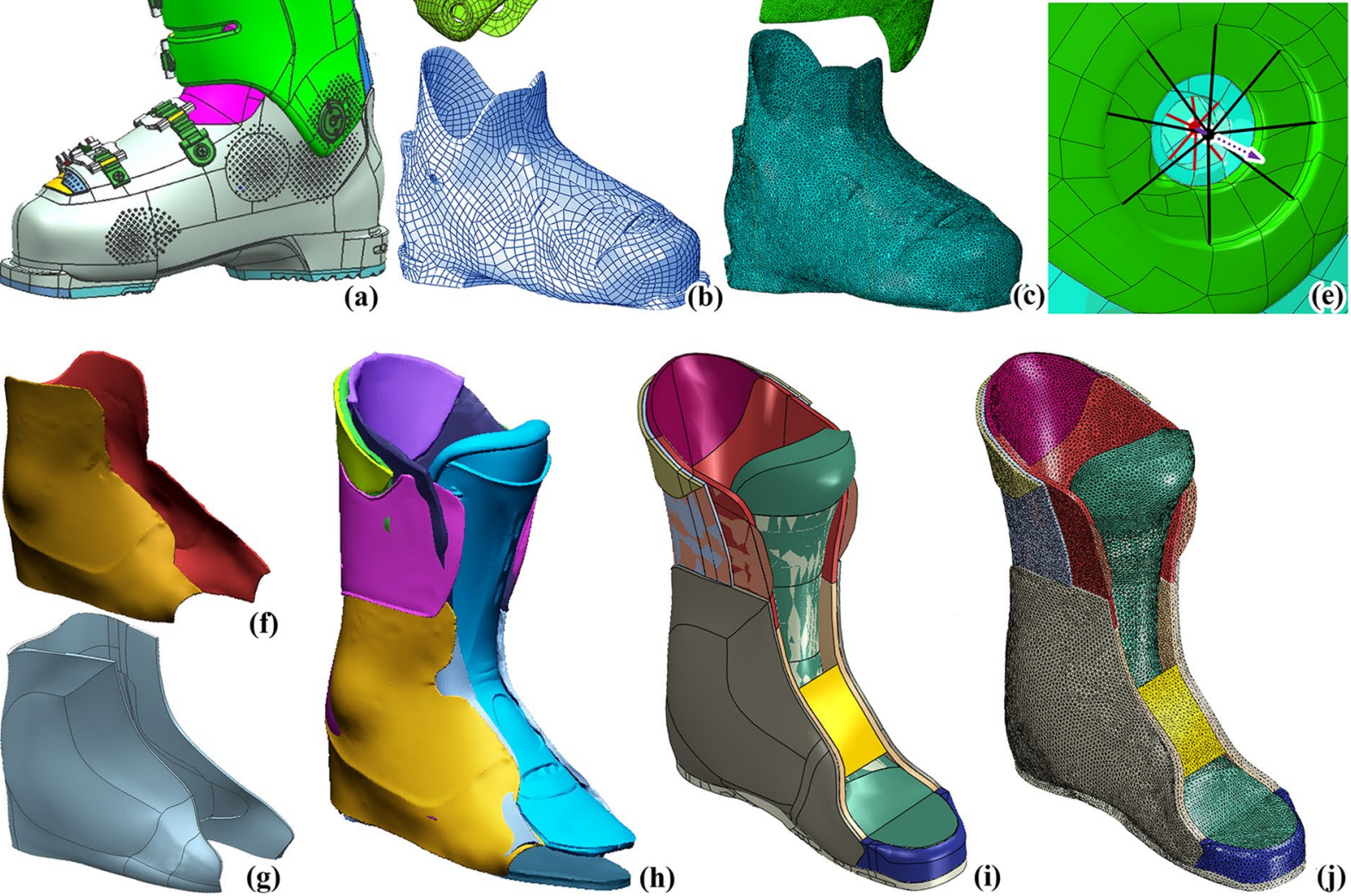

(h)
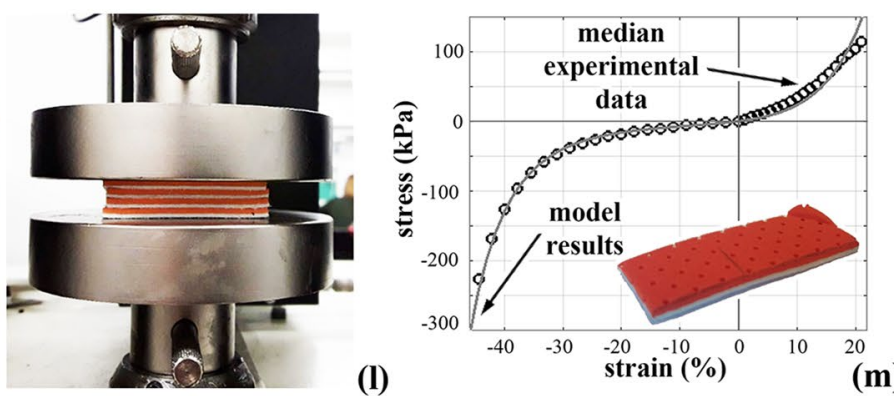

Fig. 4 3D CAD, finite element modelling of ski boot shell and liner components and constitutive analysis: a aesthetic model of the ski boot; b 3D CAD free-form models of shell components; $\mathbf{c}$ finite element models of shell components; $\mathbf{d}$ coupling of lower and upper shell components: friction contact (0.2 friction coefficient) characterises the typical interaction condition; tie constraint ensured the coupling by screws or nails in the bottom region (blue rectangle); the red rectangle highlights the region of sub-plot $\mathbf{e}$, where multipoint constraints limit the relative motion of upper and lower shells to a rotation around a specific local axis (violet arrow); f STL model from laser scanner acquisition of a specific layer on the liner and $\mathbf{g}$ 3D CAD model; $\mathbf{h}$ STL, $\mathbf{i}$ 3D CAD and $\mathbf{j}$ finite element models of all the liner and cuff layers. Finite element discretization was performed by means of both four-node tetrahedral elements and three-node shell elements; $\mathbf{k}$ tensile specimen and tensile test, according to EN ISO 1798:2008, on a specific liner material; $\mathbf{I}$ compression specimen and compression test, according to EN ISO 3386-1:1997/A1 2010; m experimental data (empty circles) from tensile and compression tests on a specific layer of the liner and results from constitutive fit with a first-order Ogden hyperelastic formulation (continuous line) 
3D models were discretised using four-node tetrahedral elements with an average size that ranged between 0.4 and $2.0 \mathrm{~mm}$ of mesh seed, depending on the region meshed (Fig. 4c). Furthermore, the use of tie constraints, multi-point constraints and the introduction of frictional contact conditions (using 0.2 static friction coefficient [64-66]) allowed for the correct description of the interactions among shell components (Fig. 4d,e).

Concerning the liner and the cuff, the model must envisage the different building layers and materials to correctly interpret their different mechanical behaviour. In the first place, it was decided to acquire geometry and inner structure by means of a CT scan but, due to the similar interaction of the different materials with X-ray, the approach failed in discriminating the different layers. For this reason, laser scanning techniques were used on a dummy lower limb on which each layer was placed sequentially. Manufacturing of the dummy model required 3D printing (Materialise NV, Leuven, Belgium; PC-ABS) of the previously developed 3D CAD model of the lower limb, accounting for the external surface, such as the skin surface, of the model only. After positioning a layer, the geometry was acquired. Subsequently, Boolean operations led to preliminary STL models of the layers (Fig. 4f, h), whose subsequent processing provided 3D CAD (Fig. 4g, i) and finite element (Fig. 4j) models. Tie constraints ensured the continuity among finite element models of the different layers. Finite element discretization was performed by means of four-node tetrahedral elements, whose size ranged between 0.2 and $1.0 \mathrm{~mm}$.

The mechanical behaviour of the rigid thermoplastic components of the shells and of the liner (thermoplastic polyurethane Covestro Desmopan 3860 and 3856, respectively) was identified using technical data provided by the manufacturer. These components followed the assumption of linear elastic isotropic behaviour (tensile modulus $500 \mathrm{MPa}$ for Desmopan 3860 and $310 \mathrm{MPa}$ for Desmopan 3856 at $20{ }^{\circ} \mathrm{C}$ temperature, while 0.45 Poisson ratio was assumed for both materials), and the properties agreed with those reported elsewhere [67]. Mechanical properties of rigid thermoplastic components were assumed at $20{ }^{\circ} \mathrm{C}$ temperature, because the experimentations on the liner soft foam and fabric materials were performed at room temperature, as described in the following.

Concerning the foam and the coupled foam/fabric materials of the liner and the cuff, the materials were tested distinctively by means of quasi-static tensile (EN ISO 1798:2008; dog bone specimen shape; 40 and $10 \mathrm{~mm}$ length and width, respectively, of the central region; $10 \mathrm{~mm}$ minimum thickness; $500 \mathrm{~mm} / \mathrm{min}$ loading rate) and quasi-static compression (EN ISO 3386-1:1997/A1 2010; cylindrical or parallelepiped shape; $2500 \mathrm{~mm}^{2}$ minimum specimen section area; $10 \mathrm{~mm}$ minimum specimen thickness; $100 \mathrm{~mm} / \mathrm{min}$ loading rate) tests. With specific regard to thermoformed elements, experimentations were performed on specimens that were cut out from the manufactured components. The analysis of the experimental results suggested the use of a first-order Ogden hyperelastic formulation [25]. The inverse analyses of such compression and tensile tests led to the materials' parameters (Fig. 4k-m). More details on experimental activities on liner materials are reported in Online Resource 1.

The final finite element discretization of the ski boot components led to about 2 million elements (four-node tetrahedral brick elements and three-node triangular shell elements), 600,000 nodes and 2.3 million variables.

\subsection{Computational analysis of ski boot buckling process}

CAD virtual translations and rotations made it possible to position the ski boot liner and the cuff within the shells (Fig. 5a). Friction contact conditions defined the interaction among the liner, cuff and shells ( 0.3 static friction coefficient for interaction between shells and liner/cuff, 0.4 static friction coefficient for self-interaction between liner and cuff surfaces). Again, CAD virtual position procedures, together with minimal Boolean operations, allowed for positioning of the lower limb model within the ski boot (Fig. 5b). Considering the presence of a sock, a friction contact condition specified the interactions between lower limb and ski boot assuming a 0.4 static friction coefficient. The specific static friction coefficients were assumed depending on the specific materials that build up the analysed ski boot [64-66]. Nevertheless, the computational approach makes it possible to analyse the influence of different friction properties on the interaction phenomena between the ski boot and lower limb. Indeed, many different factors (materials, surface characteristics, temperature, etc.) may influence friction conditions.

The final model of the system composed of the ski boot and lower limb resulted in about 5 million elements, 1.3 million nodes and more than 5 million variables.

To simulate the buckling of the ski boot, the buckles and buckle hooks were simplified to include only their centre points, connected to the shell nodes by means of multi-point constraints. The connection of centre points by means of connector elements (Fig. 5c) made it possible to describe the buckling process by means of reducing the length of the connectors (Fig. 5d) [68]. The toe and heel lugs were fully constrained, as for the top region of the tibial head. The complexity of interactions phenomena among model components and the complexity of materials behaviour suggested assuming the explicit dynamic approach [69] of the general-purpose finite element code Abaqus Explicit 2018 (Dassault Systèmes, France). The mechanical behaviour of biological tissues was specified by the previously described visco-hyperelastic formulations, which were implemented 

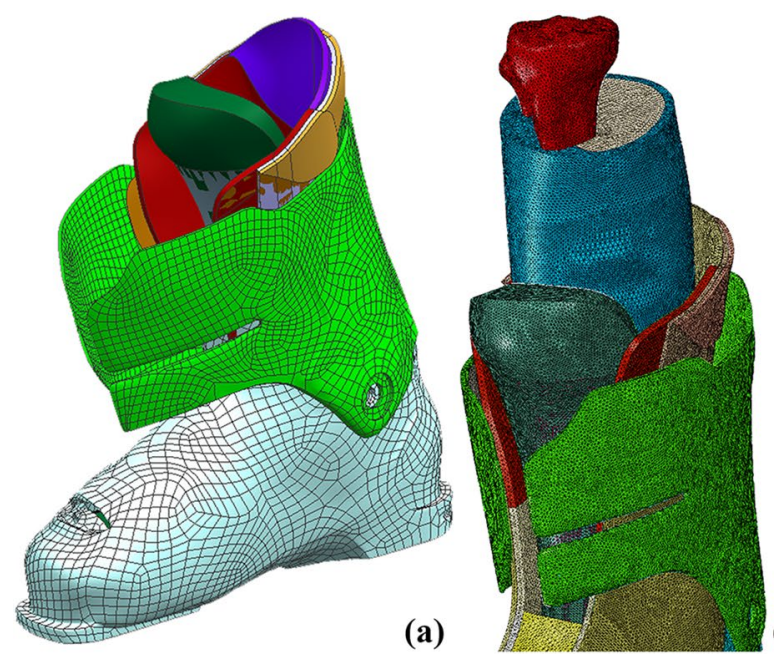

(b)
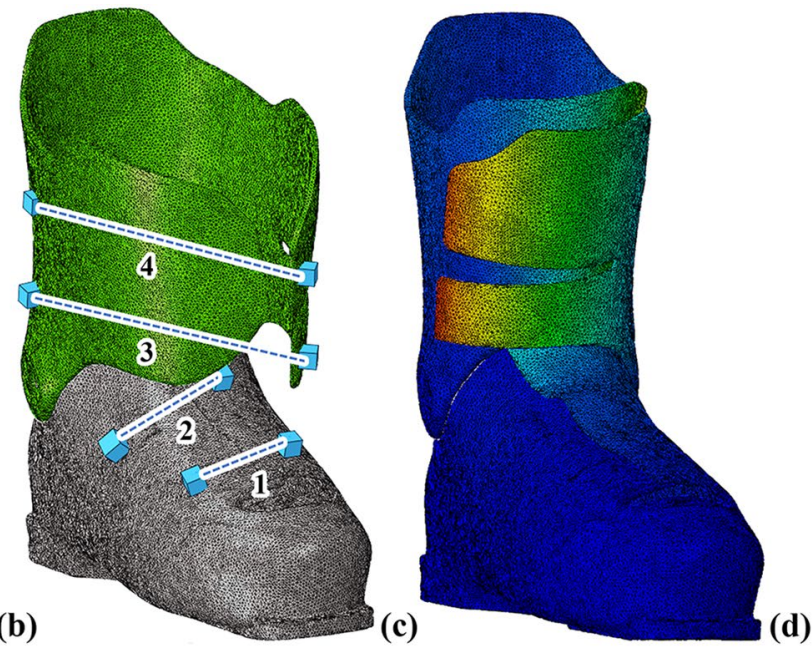

lower limb; c finite element schematization of buckles by means of connector elements 1, 2, 3 and 4; $\mathbf{d}$ buckled configuration of ski boot shells

sensor, Freescale Semiconductor, USA) utilising temperature compensation and operating with a pressure range of $50 \mathrm{kPa}$. The signal was acquired by an Arduino Nano microcontroller (Arduino.cc) using the internal AD 10 bit converter whose minimal measurable pressure change was $0.049 \mathrm{kPa}$. The system was calibrated by comparing the measures with those from a manometer (LEX 1, Italmanometri, Reggio Emilia, Italy; pressure measurement range: $-1 \div 2$ bar, resolution: 0.1 mbar). All the experiments were performed at room temperature.

Before experimentally measuring the interaction pressure, the angle between the tibia and floor was evaluated by means of a goniometer (RVS Goniometer, Baseline Evaluation Instruments, New York, USA), providing results ranging between $74^{\circ}$ and $79^{\circ}$. Angle measurements were performed by assuming a relax position of the tester.

To perform the experimental analysis of the ski boot's buckling, a coding procedure was assumed. The buckles were numbered starting from the foot tip toward the top of the cuff (Fig. 6a) and each hook was numbered according to their proximity to the buckle hand (Fig. 6b). Thus, it was possible to codify each possible buckling configuration with four numbers representing the buckle (by the position of the number) and the buckle hook chosen (with the value of the number). This coding system allowed for the acquisition of data regarding the different buckling configurations, in terms of both pressure and displacements between the buckle and the corresponding buckle hooks (Fig. 6c).

Buckles displacements were measured with reference to the initial configuration of the unbuckled ski boot. In this sense, the relative displacement exactly defines the shortening of connector elements (Fig. 4c) that was applied to computationally simulate the buckling process. 


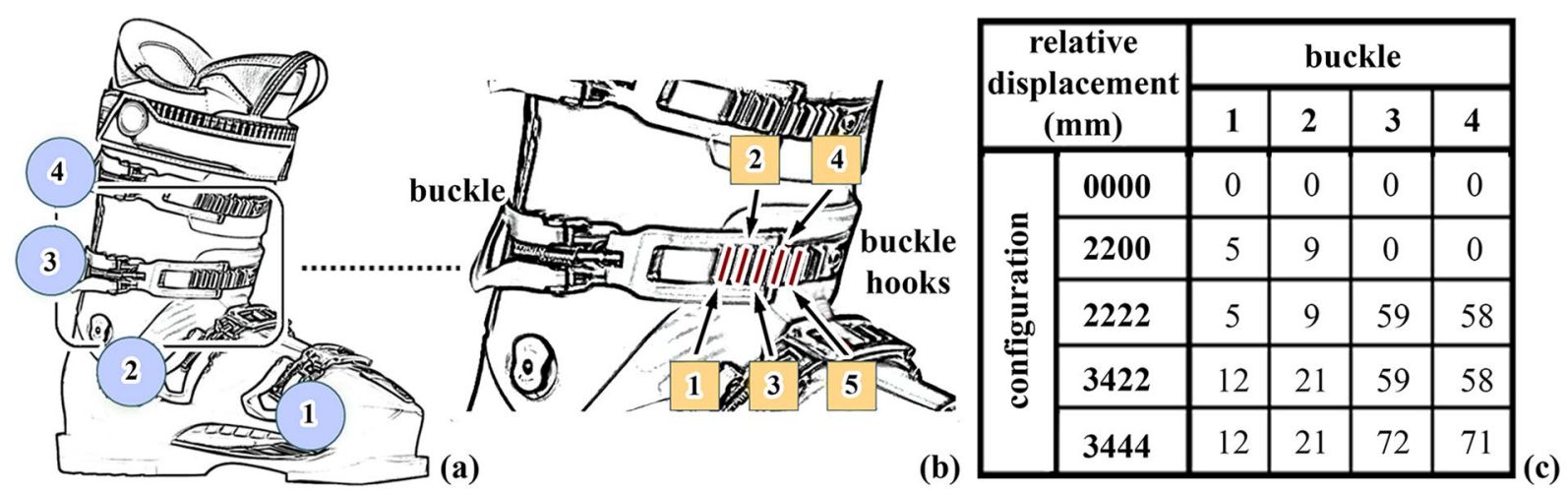

Fig. 6 Experimental coding procedure of ski boot buckling: a definition of buckles numbers; $\mathbf{b}$ definition of buckle hooks numbers; $\mathbf{c}$ relative displacement between buckle and buckle hooks, which have been measured with reference to the initial unbuckled configuration

In detail, buckling was done by lacing up the first and the second buckles on the second hook, as configuration 2200. Afterward, the process was carried on the third and fourth buckles, leading to configuration 2222. Following the previous step, the first and the second buckles were adjusted to reach configuration 3422 , and finally the third and the fourth buckles were tightened to the fourth hook, reaching configuration 3444 (Fig. 6c).

Experimental information was necessary to perform computational analyses whose results can be compared with experimental data. Aiming to provide general data, measurements were performed on six participants, whose anthropometric parameters, such as foot length, ball width, calf circumference, long heel length and lower leg length, were similar $( \pm 10 \%)$ to the developed computational model of the lower limb (Fig. 2a). The study was approved by the Ethical Committee of the University of Verona (2019-UNVRCLE-0434163, Department of Neurosciences, Biomedicine and Movement, 28th November 2019) and performed in accordance with the Declaration of Helsinki. All the participants were informed about the test purpose and procedures of the study, and signed an informed consent for the scientific implementation, application and processing of experimental results and data.

\section{Results}

The computational analyses of the buckling process provided data about the forces that were required to shorten the connector elements (Fig. 6c), as the buckling forces, which are summarised in Table 2.

Concerning the interaction pressure between the lower limb and ski boot at the tibial region, experimental data and computational results were compared (Fig. 7).

The distributions of the interaction pressure between the lower limb and ski boot and compressive strain within
Table 2 Results from computational analysis of ski boot buckling: forces at the different buckles for different configurations

\begin{tabular}{llllll}
\hline $\begin{array}{l}\text { Buckle } \\
\text { force }(N)\end{array}$ & & \multicolumn{3}{l}{ Buckle } & \\
\cline { 3 - 6 } & & 1 & 2 & 3 & 4 \\
\hline configuration & 0000 & 0 & 0 & 0 & 0 \\
& 2200 & 0 & 55 & 0 & 0 \\
& 2222 & 22 & 102 & 0 & 0 \\
& 3422 & 4 & 175 & 7 & 49 \\
& 3444 & 4 & 187 & 13 & 102 \\
\hline
\end{tabular}

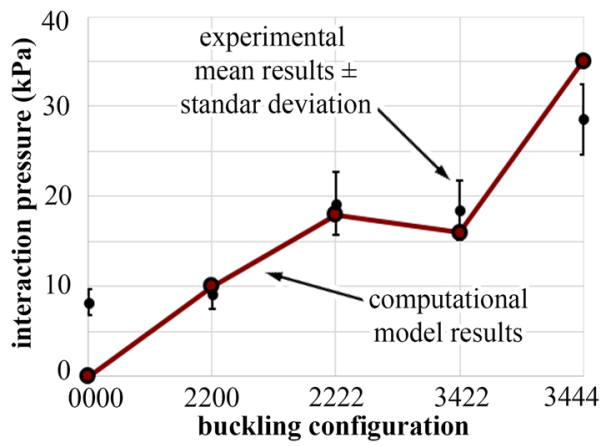

Fig. 7 Comparison of experimental data and computational results: interaction pressure between lower limb and ski boot at the tibial region for the different buckling configurations. Experimental results report both mean values and standard deviation, which ranges between 13 and $18 \%$

the lower limb tissues are reported in Fig. 8 for the different buckling configurations. The maximum values of interaction pressure and compressive strain were reached for configurations 3422 and 3444 in correspondence of the soft tissues of the metatarsal and calcaneal regions and the anterior lower leg region. Configuration 3422 showed an interaction pressure of $25 \mathrm{kPa}$ and a compressive strain of $18 \%$, while configuration 3444 showed a high increment 
Fig. 8 Results from the computational analysis of ski boot buckling at different configurations: a contours of interaction pressure between lower limb and ski boot on the skin; $\mathbf{b}$ contours of compressive strain on a middle section of the lower limb
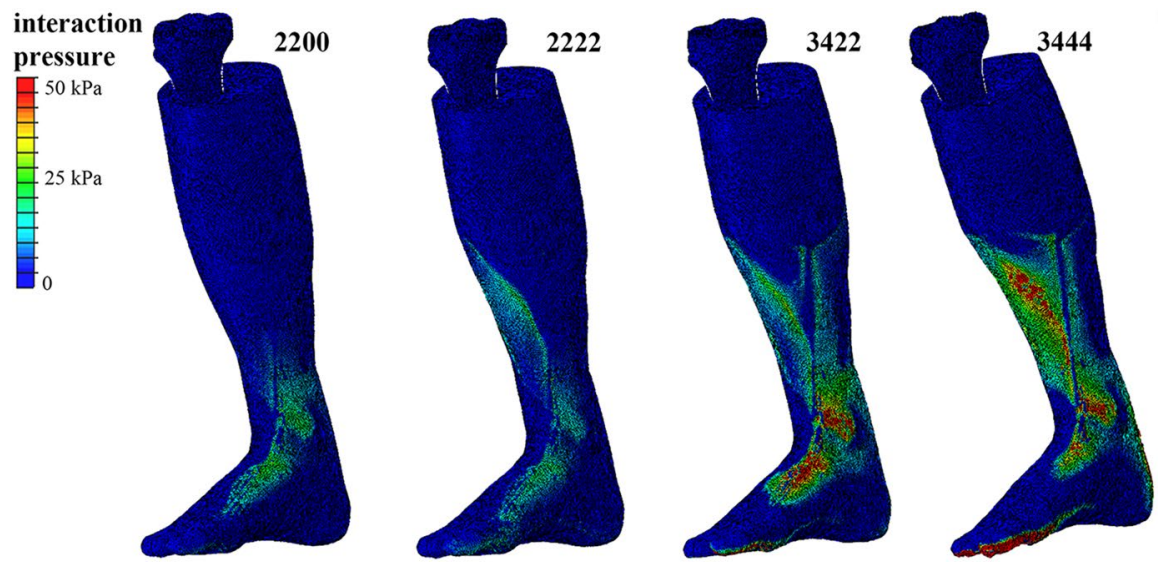

(a)
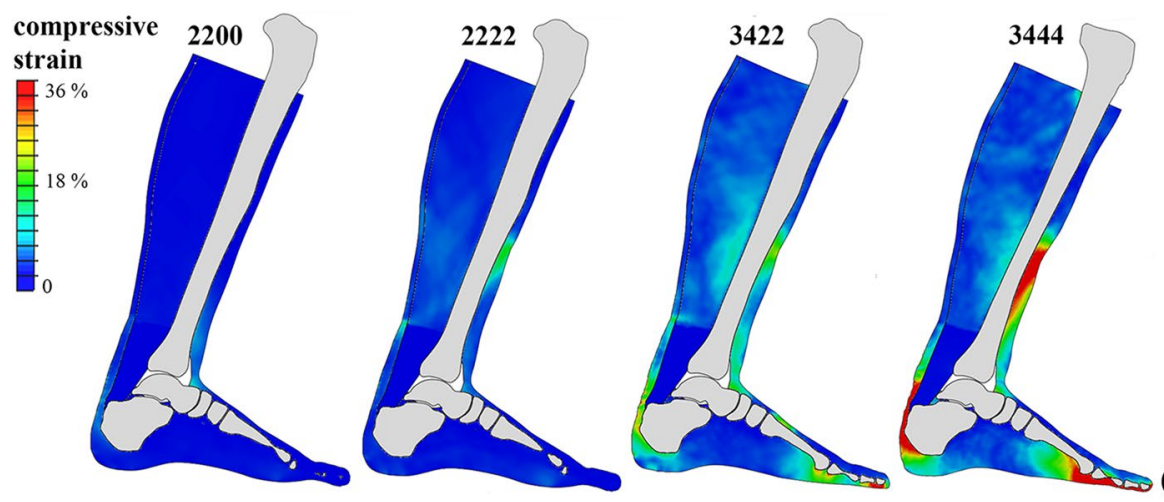

(b) of interaction pressures (up to $50 \mathrm{kPa}$ ) and compressive strains (over 36\%).

Figure 9 provides the distribution of hydrostatic pressure in the most severe buckling configuration (3444), together with a representation of blood pressure within the vascular system [70]. Analysing the hydrostatic pressure exerted on the lower limb during configuration 3444 , it is possible to observe that the local hydrostatic pressure reached values exceeding $75 \mathrm{mmHg}$, in correspondence of the calcaneal and anterior regions (Fig. 9a, b). To better evaluate the influence of hydrostatic pressure on soft tissues functionality, typical values of blood pressure in the human organism are reported (Fig. 9c).

\section{Discussion}

The reported activities highlight the potentiality and the effectiveness of computational biomechanics for the investigation of the interaction phenomena between a ski boot and lower limb. Coupled experimental and computational activities demonstrated the dependability of the lower limb model
Fig. 9 Investigation of hydrostatic pressure: a distribution of the hydrostatic pressure within the lower limb and $\mathbf{b}$ details on a section; c blood pressure within the vascular system [70]
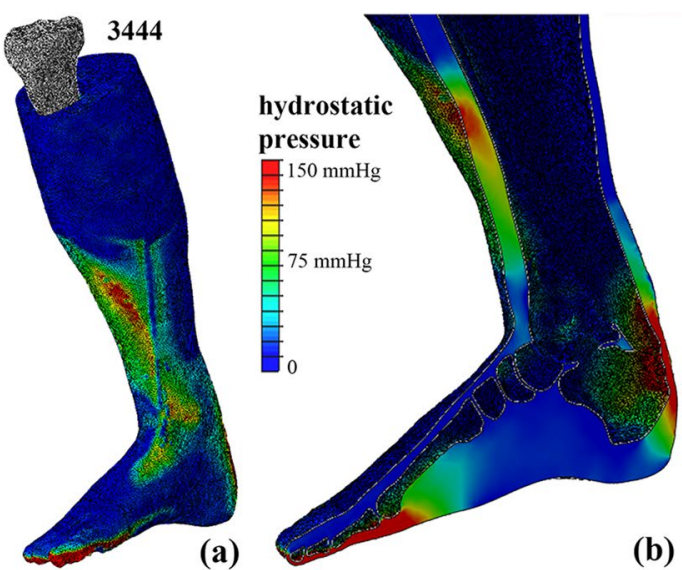

(b)

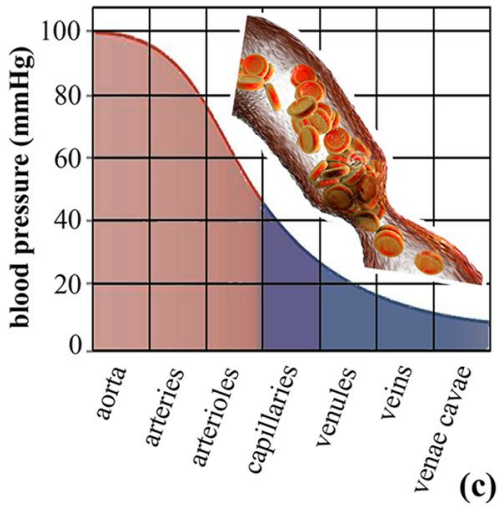


(Fig. 3) and methodologies (Fig. 7). With specific regard to the ski boot, the computational investigation of the buckling process provided values of buckling forces (Table 2) that were similar to data from experimental activities reported elsewhere [71]. Computational methods can also provide more information and data than experimental activities, like buckling forces, interaction pressure between the lower limb and ski boot (Fig. 7a), and stress and strain fields within biological tissues (Fig. 8b).

Mechanical stimuli determine many different biological effects. For example, high compressive strain values can induce tissue damage. Prolonged compression of soft tissues adjacent to bony prominences can lead to tissues degeneration, resulting in a condition called pressure-related deep tissue injury, which can develop into deep pressure ulcers and wounds. Previous studies have demonstrated that compression strains over 30\% can induce significant tissue damage [72]. High hydrostatic pressure values (Fig. 9) highlight possible occlusion of blood vessels, providing a source of vasoconstriction and explaining the "cold leg" sensation experienced by some ski boot users $[5,6]$. Such mechanobiological factors can affect the ski boot performance, comfort and ergonomics [7]. In this sense, the proposed approach defines a novel methodology for the design and the reliability assessment of ski boot geometry and materials.

Great efforts pertained to the definition of a reliable and accurate model of the lower limb, by considering the geometrical modelling of the different biological structures and the mechanical characterisation of the different biological tissues. With particular regard to parameters reported in Fig. 2a, the model is suitable for morphing procedures, aiming at interpreting the anatomical configuration of different skiers. Furthermore, tissue parameters can be modified to interpret specific situations, with particular regard to pathologic ones. On the other side, ski boot modelling was performed by considering a specific product. The action made it possible to illustrate the potentialities of the computational approach. The same methodology can be extended to analyse the interaction phenomena between the lower limb and different ski boots.

The presented results are promising, but it is worth noticing some critical points in the approach presented here. To reach an appreciable level of reliability, the model was discretised with many finite elements, thus leading to computationally heavy models and simulations. The process for the acquisition of the liner's geometry, due to the complex geometries and number of layers, also remains a complex and long process. A further limitation pertains to the Velcro strap that usually characterises ski boots, and was not included within the model. Nevertheless, the Velcro strap mainly acts on the upper region of the cuff and it was not tied during experimental measurements of interaction pressure.
The proposed model has been exploited to analyse a static condition, such as the interaction phenomena that occur between the lower limb and ski boot in a steady state situation. The activities aimed at analysing the influence of incremental ski boot buckling on mechanical stimulation of biological tissues. Both the proposed experimental and computational methods can be further exploited to analyse dynamic conditions. Indeed, plantar- and dorsiflexion that occur during skiing affect interactions between the biological structures and the ski boot. Further activities are under development to analyse these topics. Furthermore, aiming to a more accurate reliability assessment of interaction pressure measurements, pressure sensors could be located also in other positions, such as the metatarsal and the calcaneal region of the foot, and the anterior sole, as reported in [73].

Another limitation of the proposed investigations pertains to temperature. Ski boots ergonomics was here analysed at room temperature, but they are usually worn outdoors in sub-zero temperature (Celsius) conditions. Unfortunately, the experimental facilities available made it possible to characterise the mechanical behaviour of liner materials at room temperature only. Furthermore, the experimental evaluation of interaction pressure during the buckling process was performed at room temperature, and such data were mandatory for the reliability assessment of the overall computational model. Anyway, the paper aims at providing a novel computational approach and framework for the investigation of ski boot functionality and interaction phenomena with lower limb tissues. Given materials parameters at a specific temperature, the model should allow for analyses at such temperature, although its accuracy would need to be reassessed at this temperature.

\section{Conclusions}

The developed activities highlight the potentialities of computational biomechanics for both the investigation of sport devices reliability and the design of better equipment. Computational methods provide data and information that barely can be achieved by means of experimental activities. Furthermore, computational models, once they have been developed, can be exploited to analyse a broad scenario of situations, considering many conformations of the device, many anatomical configurations of the user and many loading conditions. With specific regard to the here developed investigations, aside from being a reliable base for the modelling of the lower limb and ski boot interaction, the reported approach and models are also suitable to be coupled with morphing techniques based on acquiring the skier's morphometric data by means of laser scanning. This non-invasive technique should allow for the acquisition of the most 
relevant data for the designing of a tailored ski boot, or for the evaluation of ski boot suitability for the specific user.

Supplementary Information The online version contains supplementary material available at https://doi.org/10.1007/s12283-021-00352-3.

Authors' contributions CGF, AA and IT: developed the computational models and performed the computational analyses; $\mathrm{CZ}$ and LB: ideated and performed the experimental investigations for liner model development and pressure data acquisition; ELC: conceived of the study, participated in its design and coordination, and wrote the manuscript.

Funding Open access funding provided by Università degli Studi di Padova within the CRUI-CARE Agreement. This study has been supported by Regione Veneto (POR-FESR 2014-2020, Asse 1, Azione 1.1.4), projects "SMAC - Smart and Creative Technologies for the Sportsystem" and "SAFE - Smart creAtivity for saFety and rEstart", and by Italian Ministry of Education, Research and University MIUR, project FISR2019_03221 "CECOMES_CEntro di studi sperimentali e COmputazionali per la ModElliStica applicata alla chirurgia".

\section{Declarations}

Conflicts of interest The authors declare that they have no competing interests.

Open Access This article is licensed under a Creative Commons Attribution 4.0 International License, which permits use, sharing, adaptation, distribution and reproduction in any medium or format, as long as you give appropriate credit to the original author(s) and the source, provide a link to the Creative Commons licence, and indicate if changes were made. The images or other third party material in this article are included in the article's Creative Commons licence, unless indicated otherwise in a credit line to the material. If material is not included in the article's Creative Commons licence and your intended use is not permitted by statutory regulation or exceeds the permitted use, you will need to obtain permission directly from the copyright holder. To view a copy of this licence, visit http://creativecommons.org/licenses/by/4.0/.

\section{References}

1. Hunter R (199AD) Skiing Injuries. J Showa Med Assoc. 27:381389. https://doi.org/10.14930/jsma1939.21.11_729

2. Petrone N, Marcolin G, Panizzolo FA (2013) The effect of boot stiffness on field and laboratory flexural behavior of alpine ski boots. Sport Eng 16:265-280. https://doi.org/10.1007/ s12283-013-0133-Z

3. Fauland G, Hofer P, Nachbauer W, Bechtold T (2012) Moisture management properties of ski-boot liner materials. Text Res J 82:99-107. https://doi.org/10.1177/0040517511418558

4. Colonna M, Moncalero M, Nicotra M et al (2014) Thermal behaviour of ski-boot liners: Effect of materials on thermal comfort in real and simulated skiing conditions. Procedia Eng 72:386-391. https://doi.org/10.1016/j.proeng.2014.06.066

5. Höflin F, Kempi V, van der Linden W, Ringquist I (1976) Effect of flow material ski boots on foot circulation. Orthop Clin North Am 7(1):151-157

6. Hofer P, Hasler M, Fauland G et al (2011) Temperature, relative humidity and water absorption in ski boots. Procedia Eng 13:44-50. https://doi.org/10.1016/j.proeng.2011.05.049
7. Colonna M, Moncalero M, Gioia C et al (2015) Effect of compression on thermal comfort of ski boots. Procedia Eng 112:134-139. https://doi.org/10.1016/j.proeng.2015.07.188

8. Schaff P, Senner V, Kaiser F. Skiing and Science (eds. Müller E et al.). London: E \& FN Spon; London; 1997. p. 159-172.

9. Pinter M, Eckelt M, Schretter H (2010) Evaluation of ski boot fitting characteristics by means of different pressure distribution measurements. Procedia Eng 2:2875-2880. https://doi.org/10. 1016/j.proeng.2010.04.081

10. Carniel EL, I, Toniolo CG, Fontanella, (2020) Computational biomechanics : in-silico tools for the investigation of surgical procedures and devices. Bioeng. https://doi.org/10.3390/bioen gineering 7020048

11. Lohman TJ, Roache AF, Martorell R (1992) Anthropometric standardization reference manual. Med Sci Sport Exerc 24:952. https://doi.org/10.1249/00005768-199208000-00020

12. McDowell MA, Fryar CD, Ogden CL (2009) Anthropometric reference data for children and adults: United States, 1988-1994 Vital and health statistics. Ser 11 Data Natl Health Survey 249:1-68

13. McDowell MA, Fryar CD, Ogden CL, Flegal KM (2008) Anthropometric reference data for children and adults: United States, 2003-2006. Natl Health Stat Report 2003-2006

14. O'Meara D, Vanwanseele B, Hunt A, Smith R (2010) The reliability and validity of a three-camera foot image system for obtaining foot anthropometrics. J Appl Biomech 26:349-356. https://doi. org/10.1123/jab.26.3.349

15. Preedy VR (2012) Handbook of anthropometry. Springer, New York

16. Taifa IW, Desai DA (2017) Anthropometric measurements for ergonomic design of students' furniture in India. Eng Sci Technol an Int J 20:232-239. https://doi.org/10.1016/j.jestch.2016.08.004

17. Jurca A, Žabkar J, Džeroski S (2019) Analysis of 1.2 million foot scans from North America. Europe and Asia Sci Rep 9:1-10. https://doi.org/10.1038/s41598-019-55432-z

18. Grassi L, Hraiech N, Schileo E, Ansaloni M, Rochette M, Viceconti M (2011) Evaluation of the generality and accuracy of a new mesh morphing procedure for the human femur. Med Eng Phys 33:112-120. https://doi.org/10.1016/j.medengphy.2010.09.014

19. Biancolini ME, Valentini PP (2018) Virtual human bone modelling by interactive sculpting, mesh morphing and force-feedback. Int J Interact Des Manuf 12:1223-1234. https://doi.org/10.1007/ s12008-018-0487-3

20. Venturato C, Pavan PG, Forestiero A et al (2014) Investigation of the biomechanical behaviour of articular cartilage in hindfoot joints. Acta Bioeng Biomech 16:57-65. https://doi.org/10.5277/ abb140207

21. Forestiero A, Carniel EL, Natali AN (2014) Biomechanical behaviour of ankle ligaments: constitutive formulation and numerical modelling. Comput Methods Biomech Biomed Engin 17:395404. https://doi.org/10.1080/10255842.2012.688105

22. Fontanella CG, Forestiero A, Carniel EL, Natali AN (2015) Investigation of the mechanical behaviour of the plantar soft tissue during gait cycle: experimental and numerical activities. Proc Inst Mech Eng Part H J Eng Med 229:713-720. https://doi.org/10. 1177/0954411915601702

23. Shin J, Yue N, Untaroiu CD (2012) A finite element model of the foot and ankle for automotive impact applications. Ann Biomed Eng 40:2519-2531. https://doi.org/10.1007/s10439-012-0607-3

24. Holzapfel G (2002) Nonlinear solid mechanics: a continuum approach for engineering science. Meccanica 37:489-490

25. Carniel EL, Gramigna V, Fontanella CG et al (2014) Characterization of the anisotropic mechanical behaviour of colonic tissues: experimental activity and constitutive formulation. Exp Physiol 99:759-771. https://doi.org/10.1113/expphysiol.2013.076091 
26. Carniel EL, Fontanella CG, Stefanini C, Natali AN (2013) A procedure for the computational investigation of stress-relaxation phenomena. Mech Time-Dependent Mater 17:25-38. https://doi. org/10.1007/s11043-013-9209-1

27. Natali AN, Fontanella CG, Carniel EL (2010) Constitutive formulation and analysis of heel pad tissues mechanics. Med Eng Phys 32:516-522. https://doi.org/10.1016/j.medengphy.2010.02.018

28. Natali AN, Fontanella CG, Carniel EL, Young JM (2011) Biomechanical behaviour of heel pad tissue: experimental testing, constitutive formulation, and numerical modelling. Proc Inst Mech Eng Part H J Eng Med 225:449-459. https://doi.org/10.1177/09544 119JEIM851

29. Fontanella CG, Favaretto E, Carniel EL, Natali AN (2014) Constitutive formulation and numerical analysis of the biomechanical behaviour of forefoot plantar soft tissue. Proc Inst Mech Eng Part H J Eng Med 228:942-951. https://doi.org/10.1177/0954411914 551852

30. Fontanella CG, Nalesso F, Carniel EL, Natali AN (2016) Biomechanical behavior of plantar fat pad in healthy and degenerative foot conditions. Med Biol Eng Comput 54:653-661. https://doi. org/10.1007/s11517-015-1356-x

31. Miller-Young JE, Duncan NA, Baroud G (2002) Material properties of the human calcaneal fat pad in compression: experiment and theory. J Biomech 35:1523-1531. https://doi.org/10.1016/ S0021-9290(02)00090-8

32. Ledoux WR, Blevins JJ (2007) The compressive material properties of the plantar soft tissue. J Biomech 40:2975-2981. https:// doi.org/10.1016/j.jbiomech.2007.02.009

33. Pai S, Ledoux WR (2012) The shear mechanical properties of diabetic and non-diabetic plantar soft tissue. J Biomech 45:364-370. https://doi.org/10.1016/j.jbiomech.2011.10.021

34. Ledoux WR, Meaney DF, Hillstrom HJ (2004) A quasi-linear, viscoelastic, structural model of the plantar soft tissue with frequency-sensitive damping properties. J Biomech Eng 126:831837. https://doi.org/10.1115/1.1824133

35. Brown CP, Crawford RW, Oloyede A (2007) Indentation stiffness does not discriminate between normal and degraded articular cartilage. Clin Biomech 22:843-848. https://doi.org/10.1016/j.clinb iomech.2007.04.013

36. Pavan PG, Pachera P, Stecco C, Natali AN (2014) Constitutive modeling of time-dependent response of human plantar aponeurosis. Comput Math Methods Med. https://doi.org/10.1155/2014/ 530242

37. Natali AN, Pavan PG, Stecco C (2010) A constitutive model for the mechanical characterization of the plantar fascia. Connect Tissue Res 51:337-346. https://doi.org/10.3109/030082009033891 27

38. Pavan PG, Stecco C, Darwish S et al (2011) Investigation of the mechanical properties of the plantar aponeurosis. Surg Radiol Anat 33:905-911. https://doi.org/10.1007/s00276-011-0873-z

39. Forestiero A, Carniel EL, Venturato C, Natali AN (2013) Investigation of the biomechanical behaviour of hindfoot ligaments. Proc Inst Mech Eng Part H J Eng Med 227:683-692. https://doi.org/10. $1177 / 0954411913481172$

40. Attarian DE, McCrackin HJ, DeVito DP et al (1985) Biomechanical characteristics of human ankle ligaments. Foot Ankle 6:54-58. https://doi.org/10.1177/107110078500600202

41. Funk JR, Hall GW, Crandall JR, Pilkey WD (2000) Linear and quasi-linear viscoelastic characterization of ankle ligaments. J Biomech Eng 122:15-22. https://doi.org/10.1115/1.429623

42. Quapp KM, Weiss JA (1997) A material characterization of human medial collateral ligament. Am Soc Mech Eng Bioeng Div BED 36:191-192

43. Weiss JA, Gardiner JC, Bonifasi-Lista C (2002) Ligament material behavior is nonlinear, viscoelastic and rate-independent under shear loading. J Biomech 35:943-950. https://doi.org/10.1016/ S0021-9290(02)00041-6

44. Fontanella CG, Natali AN, Carniel EL (2017) Numerical analysis of the foot in healthy and degenerative conditions. J Mech Med Biol 17:1-14. https://doi.org/10.1142/S0219519417500956

45. Abdalbary SA, Elshaarawy EAA, Khalid BEA (2016) Tensile properties of the deep transverse metatarsal ligament in hallux valgus a consort-compliant article. Med (United States) 95:1-5. https://doi.org/10.1097/MD.0000000000002843

46. Goske S, Erdemir A, Petre M et al (2006) Reduction of plantar heel pressures: Insole design using finite element analysis. J Biomech 39:2363-2370. https://doi.org/10.1016/j.jbiomech.2005.08. 006

47. A., Viverios, M.L., Ulbrecht, J.S. and Cavanagh, P.R., 2004. Hyperelastic properties of normal and diabetic heel pads from an inverse finite element model of indentation. In 28th Annual Meeting of the American Siciety of Biomechanics. Portland, OR; USA.

48. Carniel TA, Fancello EA (2017) A transversely isotropic coupled hyperelastic model for the mechanical behavior of tendons. J Biomech 54:49-57. https://doi.org/10.1016/j.jbiomech.2017.01.042

49. Csapo R, Maganaris CN, Seynnes OR, Narici MV (2010) On muscle, tendon and high heels. J Exp Biol 213:2582-2588. https://doi. org/10.1242/jeb.044271

50. Couppé C, Svensson RB, Kongsgaard M et al (2016) Human Achilles tendon glycation and function in diabetes. J Appl Physiol 120:130-137. https://doi.org/10.1152/japplphysiol.00547.2015

51. Böl M, Ehret AE, Leichsenring K, Ernst M (2015) Tissue-scale anisotropy and compressibility of tendon in semi-confined compression tests. J Biomech 48:1092-1098. https://doi.org/10.1016/j. jbiomech.2015.01.024

52. Morrow DA, Haut Donahue TL, Odegard GM, Kaufman KR (2010) Transversely isotropic tensile material properties of skeletal muscle tissue. J Mech Behav Biomed Mater 3:124-129. https:// doi.org/10.1016/j.jmbbm.2009.03.004

53. Avril S, Bouten L, Dubuis L et al (2010) Mixed experimental and numerical approach for characterizing the biomechanical response of the human leg under elastic compression. J Biomech Eng. https://doi.org/10.1115/1.4000967

54. Fontanella CG, Carniel EL, Forestiero A, Natali AN (2014) Investigation of the mechanical behaviour of the foot skin. Ski Res Technol 20:445-452. https://doi.org/10.1111/srt.12139

55. Ankersen J (1999) Puncture resistance and tensile strength of skin simulants. Proc Inst Mech Eng Part H J Eng Med 213:493-501. https://doi.org/10.1243/0954411991535103

56. Shergold OA, Fleck NA, Radford D (2006) The uniaxial stress versus strain response of pig skin and silicone rubber at low and high strain rates. Int J Impact Eng 32:1384-1402. https://doi.org/ 10.1016/j.ijimpeng.2004.11.010

57. Wu JZ, Cutlip RG, Andrew ME, Dong RG (2007) Simultaneous determination of the nonlinear-elastic properties of skin and subcutaneous tissue in unconfined compression tests. Ski Res Technol 13:34-42. https://doi.org/10.1111/j.1600-0846.2007.00182.x

58. Erdemir A, Sirimamilla PA, Halloran JP, Van Den Bogert AJ (2009) An elaborate data set characterizing the mechanical response of the foot. J Biomech Eng 131:1-6. https://doi.org/10. $1115 / 1.3148474$

59. Natali AN, Fontanella CG, Carniel EL (2012) Constitutive formulation and numerical analysis of the heel pad region. Comput Methods Biomech Biomed Engin 15:401-409. https://doi.org/10. 1080/10255842.2010.539561

60. Ozeki S, Yasuda K, Kaneda K, Yamakoshi K, Yamanoi T (2002) Simultaneous strain measurement with determination of a zero strain reference for the medial and lateral ligaments of the ankle. Foot Ankle Int 23:825-832. https://doi.org/10.1177/1071100702 02300909 
61. Fontanella CG, Matteoli S, Carniel EL et al (2012) Investigation on the load-displacement curves of a human healthy heel pad: In vivo compression data compared to numerical results. Med Eng Phys 34:1253-1259. https://doi.org/10.1016/j.medengphy.2011. 12.013

62. Matteoli S, Fontanella CG, Carniel EL et al (2013) Investigations on the viscoelastic behaviour of a human healthy heel pad: in vivo compression tests and numerical analysis. Proc Inst Mech Eng Part H J Eng Med 227:334-342. https://doi.org/10.1177/09544 11912465061

63. Forestiero A, Carniel EL, Fontanella CG, Natali AN (2017) Numerical model for healthy and injured ankle ligaments. Australas Phys Eng Sci Med 40:289-295. https://doi.org/10.1007/ s13246-017-0533-7

64. Capanidis D, Sokolska J (2018) Effect of contact pressure and sliding speed on the friction of polyurethane elastomer (EPUR) during sliding on steel under water wetting conditions. Open Eng 8:545-551. https://doi.org/10.1515/eng-2018-0064

65. Lafaye S, Gauthier C, Schirrer R (2006) Analysis of the apparent friction of polymeric surfaces. J Mater Sci 41:6441-6452. https:// doi.org/10.1007/s10853-006-0710-7

66. Moriyasu K, Nishiwaki T, Shibata K, Yamaguchi T, Hokkirigawa K (2019) Friction control of a resin foam/rubber laminated block material. Tribol Int 136:548-555. https://doi.org/10.1016/j.tribo int.2019.04.024

67. Nicotra M, Moncalero M, Colonna M (2014) Effect of the viscoelastic properties of thermoplastic polymers on the flexural and rebound behaviours of ski boots for alpine skiing. Proceed Inst Mech Eng Part P: J Sports Eng Technol 229:199-210. https://doi. org/10.1177/1754337114564481

68. Simulia DS (2014) Abaqus 6.14. Abaqus 6.14 analysis user's guide

69. Belytschko T, Liu WK, Moran B, Elkhodary K (2014) Nonlinear finite elements for continua and structures, 2nd edn. John wiley \& sons, U.S.

70. Krams R, Bäck M (2017) The ESC textbook of vascular biology. Oxford Medicine Press, Oxford

71. Petrone N. Science and skiing VI (eds.: Müller E, Kröll J, Lindinger S, Pfusterschmied J, Stöggl T). Aachen: Meyer and Meyer Verlag; 2014. p. 268 - 278. 2014

72. Ceelen KK, Stekelenburg A, Loerakker S et al (2008) Compression-induced damage and internal tissue strains are related. J Biomech 41:3399-3404. https://doi.org/10.1016/j.jbiomech.2008.09. 016

73. Colonna M, Pazi N, Moncalero M, Gioia C, De Bon F, Giovanelli D, Farella E (2017) Thermo-formation process of plastic shells for winter sport boots for improved comfort. Sports Eng 20:275-282. https://doi.org/10.1007/s12283-017-0247-9

Publisher's Note Springer Nature remains neutral with regard to jurisdictional claims in published maps and institutional affiliations. 